\title{
Development of very large electrode arrays for epiretinal stimulation (VLARS)
}

Florian Waschkowski ${ }^{1}$, Stephan Hesse ${ }^{2}$, Anne Christine Rieck², Tibor Lohmann², Claudia Brockmann³, Thomas Laube ${ }^{3}$, Norbert Bornfeld ${ }^{3}$, Gabriele Thumann ${ }^{2,4}$, Peter Walter ${ }^{2 *}$, Wilfried Mokwa', Sandra Johnen ${ }^{2}$ and Gernot Roessler ${ }^{2}$

\footnotetext{
* Correspondence: pwalter@ukaachen.de 2Department of Ophthalmology, University Hospital Aachen, RWTH Aachen University, Pauwelsstr 30, 52074 Aachen, Germany Full list of author information is available at the end of the article
}

\begin{abstract}
Background: Retinal implants have been developed to treat blindness causing retinal degenerations such as Retinitis pigmentosa (RP). The retinal stimulators are covering only a small portion of the retina usually in its center. To restore not only central vision but also a useful visual field retinal stimulators need to cover a larger area of the retina. However, large area retinal stimulators are much more difficult to implant into an eye. Some basic questions concerning this challenge should be answered in a series of experiments.
\end{abstract}

Methods: Large area retinal stimulators were fabricated as flexible multielectrode arrays (MEAs) using silicon technology with polyimide as the basic material for the substrate. Electrodes were made of gold covered with reactively sputtered iridium oxide. Several prototype designs were considered and implanted into enucleated porcine eyes. The prototype MEAs were also used as recording devices.

Results: Large area retinal stimulator MEAs were fabricated with a diameter of $12 \mathrm{~mm}$ covering a visual angle of $37.6^{\circ}$ in a normal sighted human eye. The structures were flexible enough to be implanted in a folded state through an insertion nozzle. The implants could be positioned onto the retinal surface and fixated here using a retinal tack. Recording of spontaneous activity of retinal neurons was possible in vitro using these devices.

Conclusions: Large flexible MEAs covering a wider area of the retina as current devices could be fabricated using silicon technology with polyimide as a base material. Principal surgical techniques were established to insert such large devices into an eye and the devices could also be used for recording of retinal neural activity.

Keywords: Retinal prosthesis, Artificial vision, Retinitis pigmentosa, Blindness, Rehabilitation, Vitreoretinal surgery, Silicon wafer Technology, Polyimide, Neurostimulation

\section{Background}

Retinal degenerations such as Retinitis pigmentosa (RP) may cause bilateral blindness. It is estimated that in Germany about 15,000 subjects are legally blind due to this disease. Although it is known that the disease is caused by a variety of mutations in several genes coding for key enzymes involved in retinal metabolism and light processing [1-3] no treatment is really established. Since it has been demonstrated that blind RP subjects were able to detect light spots and patterns by electrical stimulation of the retina [4-6] visual prostheses have been fabricated, approved, and used in RP patients

(c) 2014 Waschkowski et al.; licensee BioMed Central Ltd. This is an Open Access article distributed under the terms of the Creative Commons Attribution License (http://creativecommons.org/licenses/by/2.0), which permits unrestricted use, distribution, and reproduction in any medium, provided the original work is properly credited. 
[7-10]. Those implants usually consist of a multielectrode array (MEA) placed underneath the retina or onto the retinal surface and a system for signal and energy transfer [11-13]. Up to now stimulating electrode arrays were designed as very small devices for stimulation of the fovea and the perifoveal region (Table 1). However, small devices are not capable to restore a large visual field, because they simply contact only a small area of the retina, e.g. $5 \times 5 \mathrm{~mm}$ as for the ARGUS II device representing a visual angle of about $18^{\circ}$ (or $9^{\circ}$ visual field respectively) in a normal sized eye. For blind RP patients the re-activation of a large visual field is important to regain mobility and orientation. Therefore we conducted experiments in fabrication and handling to evaluate whether it is possible to build stimulators for large retinal areas. The challenge was that such large structures must have the flexibility to be inserted through a small incision into the eye without damage of the delicate electronic structures or the eye itself.

\section{Methods}

\section{Simulation of material characteristics}

To get an idea of the behavior of a polyimide foil within an eye, we created a very simple model for Comsol, a common finite element simulation software. The model consists of an incompressible spherical shell made of steel with an inner diameter of $22 \mathrm{~mm}$ and a polyimide foil with a thickness of $100 \mu \mathrm{m}$, a disc shape and a circular hole in the center of the structure. Then the foil was vertically moved into the shell until both parts came into contact. The Young's modulus of the polyimide PI2611 we used in this simulation was $8.5 \mathrm{GPa}$ and was taken from the material data sheet, the poisson ratio of 0.23 was taken from Patel et al. [14]. The friction between the polyimide foil and the shell was disregarded.

\section{Fabrication process}

Fabrication of the stimulator prototypes takes place on silicon wafers as described in detail in Figure 1. First, wafers are metalized with an aluminium sacrificial layer $(1 \mu \mathrm{m})$ and with titanium adhesion layers underneath $(50 \mathrm{~nm})$ and on top $(150 \mathrm{~nm})$. Then a first layer of polyimide PI2611 is deposited by spincoating with a thickness of $5 \mu \mathrm{m}$. It is structured by a wet etching process and baked at $400^{\circ} \mathrm{C}$ under nitrogen atmosphere for 3 hours to polymerize. Now the conducting paths, the electrodes and the contact pads are built by electroplating of gold onto the polyimide with a thickness of $2.5 \mu \mathrm{m}$. A chromium layer of $30 \mathrm{~nm}$ thickness serves as an adhesion layer. For non-electrically functional test devices we created a fake-wiring to get similar mechanical characteristics as the final electrically functional stimulators and to improve the visibility of the structures during surgery. We also tried to find the optimal positioning of the

Table 1 Overview on known sizes (width/height/thickness) of electrode arrays used in retina implants with direct retinal contact and their respective number of electrodes

\begin{tabular}{llll}
\hline Implant & Concept & \# of electrodes & Dimensions $(\mathbf{w} / \mathbf{h} / \mathbf{t}$ in $\mathbf{~ m m})$ \\
\hline Retinal implant AG & Subretinal & 1500 & $\left.3 / 3 / 0.07^{*}\right)$ \\
Argus II second sight & Epiretinal & 60 & $\left.5 / 5 / 0.5^{* *}\right)$ \\
EPIRET III & Epiretinal & 25 & $2 / 3 / 0.02[8]$ \\
\hline
\end{tabular}

*)E. Zrenner, et al. Visual Sensations Mediated By Subretinal Microelectrode Arrays Implanted into Blind Retinitis Pigmentosa Patients. Proc. 13th Annu. Conf. of the IFESS, Freiburg, 2008.

**)V. Kandagor, et al. In situ Characterization of Stimulating Microelectrode Arrays: Study of an Idealized Structure Based on Argus II Retinal implants. Implantable Neural Prostheses, Springer New York; 2010. pp. 139-56. 
a)
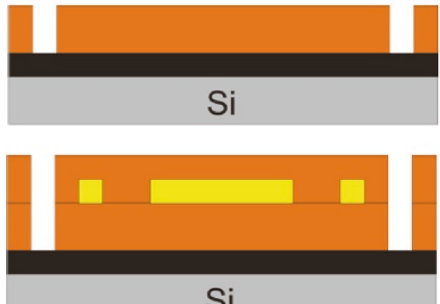

c)

$\mathrm{Si}$

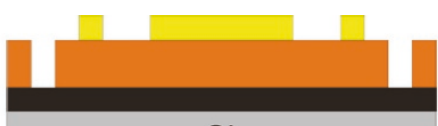

b)

$\mathrm{Si}$

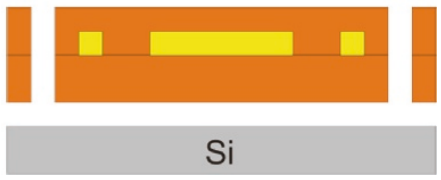

Figure 1 Fabrication process of VLARS prototypes. a) $5 \mu \mathrm{m}$ of polyimide spincoated and structured on Si-Wafer with sacrificial Al-layer (black), b) $2.5 \mu \mathrm{m}$ of electroplated gold for wiring, c) another $5 \mu \mathrm{m}$ of polyimide for isolation and protection of the wiring, d) after opening the second PI layer the electrodes are formed by another electroplating step. Further steps include: iridium oxide is sputtered and structured with a lift-off process, and the surface is coated with Parylene $C$, the electrodes are opened by a dry-etching process with oxygen plasma. Afterwards the devices are separated by etching the sacrificial Al-layer.

electrodes. During the next step a second polyimide layer $(5 \mu \mathrm{m})$ is spincoated on top of the wiring to encapsulate the gold layer. For the second generation of dummy structures we added a Parylene $C$ layer, which will be used in the final devices for additional isolation and protection against moisture. It is deposited onto the devices by a CVD process with a final thickness of $3 \mu \mathrm{m}$ and patterned by a dry-etching process with oxygen plasma. The thicknesses of all layers were chosen as in the fabrication of the EPI-RET III implant [15]. The electrodes of the final devices are formed by a second electroplating step after structuring the second PI-layer and are coated with reactively sputtered iridium oxide films with a thickness of $500 \mathrm{~nm}$. That leads, due to its high charge delivery capacity, to low electrode impedance which allows the use of low stimulation voltages [15]. Low voltages could increase the durability of the electrodes during long term stimulation experiments. The resulting devices were labeled as VLARS MEA (very large area retinal stimulator - multielectrode array).

\section{Simulation of the surgical approach}

The surgical approach was simulated by performing the procedure in enucleated porcine eyes. The setting was the same as in real surgery. Operations were performed by experienced retinal surgeons using a surgical microscope. Removal of the lens was done by phacoemulsification and removal of the vitreous by vitrectomy using a 20 gauge 3 port approach. Visualization was achieved with endoillumination and a $130^{\circ}$ contact lens placed on the corneal surface. Insertion of the device was done either by a scleral incision or by corneal incisions of $6 \mathrm{~mm}$. Insertion of the device was facilitated by using a plastic nozzle.

\section{In Vitro test on stimulation and recording capabilities}

Healthy Wistar rats were dark adapted for one hour and decapitated in deep anaesthesia. Retinas were taken from the eye under dim red light. The electrodes of the VLARS MEA were connected to a multichannel recording and stimulating device (MEA2100System, Multi Channel Systems GmbH, Reutlingen, Germany). The isolated retina was placed onto the VLARS MEA with the ganglion cell side adjacent to the electrodes. The retina was permanently superfused for at least 45 minutes with Carbogene (95\% 
O2; 5\% CO2) saturated Ames Medium (Sigma-Aldrich, St. Louis, MO, USA). For electrical stimulation a biphasic $40 \mu \mathrm{A}$ current pulse with a cathodal and anodal phase duration of $500 \mu \mathrm{s}$ was chosen. Light stimulation was done using a 1 second white light flash. The stimulation and recording was done with the MEA-Software MC_Rack (Multi Channel Systems GmbH, Reutlingen, Germany). For spike detection raw data sets of 3-5 minutes continuous recording were analyzed with a $300 \mathrm{~Hz}$ high-pass filter and a $3000 \mathrm{~Hz}$ low-pass filter and an amplification gain factor of two. The data sampling rate was $25 \mathrm{kHz} / \mathrm{channel}$. To distinguish spike waveforms on one electrode spikes were sorted computer based and manually with spike sorting software Offline SorterTM (Plexon Inc, Dallas, Tx, USA) before response analysis was done (NeuroExplorerTM, Nex Technologies, Madison, AL, USA).

All animal experiments were done in accordance with the ARVO statement for the use of animals in ophthalmic and visual research [http://www.arvo.org/About_ARVO/ Policies/Statement_for_the_Use_of_Animals_in_Ophthalmic_and_Visual_Research/] and in accordance to the German Law for Animal Protection after approval obtained from the local government.

\section{Results}

\section{Concept and assumptions}

The VLARS stimulation array is based on the fabrication process of the EPI-RET III implant, which uses the epiretinal concept, i.e. the electrode array is placed on the inner surface of the retina [16]. During implantation the device must be inserted into the eyeball through a small corneal incision. After removal of the lens and of the vitreous body the device can be pushed through the anterior chamber into the vitreous chamber of the eye. From this position it can be further moved to the retinal surface where it can be placed onto the posterior pole. Stable fixation is provided with a retinal tack. We designed a VLARS stimulator with a diameter of $12 \mathrm{~mm}$ covering an area of about $110 \mathrm{~mm}^{2}$. A retinal stimulator of that size covers a visual angle of $37.6^{\circ}$ in an eye of normal size (axial length $22.8 \mathrm{~mm}$ ) representing a visual field of $18.8^{\circ}$. With our technology, more than 250 electrodes can be realized on such a base structure for a larger field of percepts and to improve the spatial resolution in the center of the device compared to current available epiretinal technology.

\section{Design}

Shapes for the flexible base structure of the electrode array were identified which can be easily bent without damage. A foldable design is required to avoid large incisions for implantation during surgery. This may reduce the corneal incision size down to 56 millimeters. The second critical design parameter is the ability of the structure to fit to the three-dimensional curved shape of the retina. Because the implant is fabricated on the wafer level with planar processes it has a completely flat profile, while the retina is curved. For successful stimulation the device needs to be stretched or compressed to bring the electrodes in contact with the retina over the whole area. In Figure 2 results of a numerical simulation using FEM on the mechanical behavior of a polyimide foil placed in a curved shell are shown. In the cross-section it is obvious and expected that parts of the implant are not in contact with the retina due to absence of stressrelieving patterns. At the centre the foil is pressed down and in full contact with the 


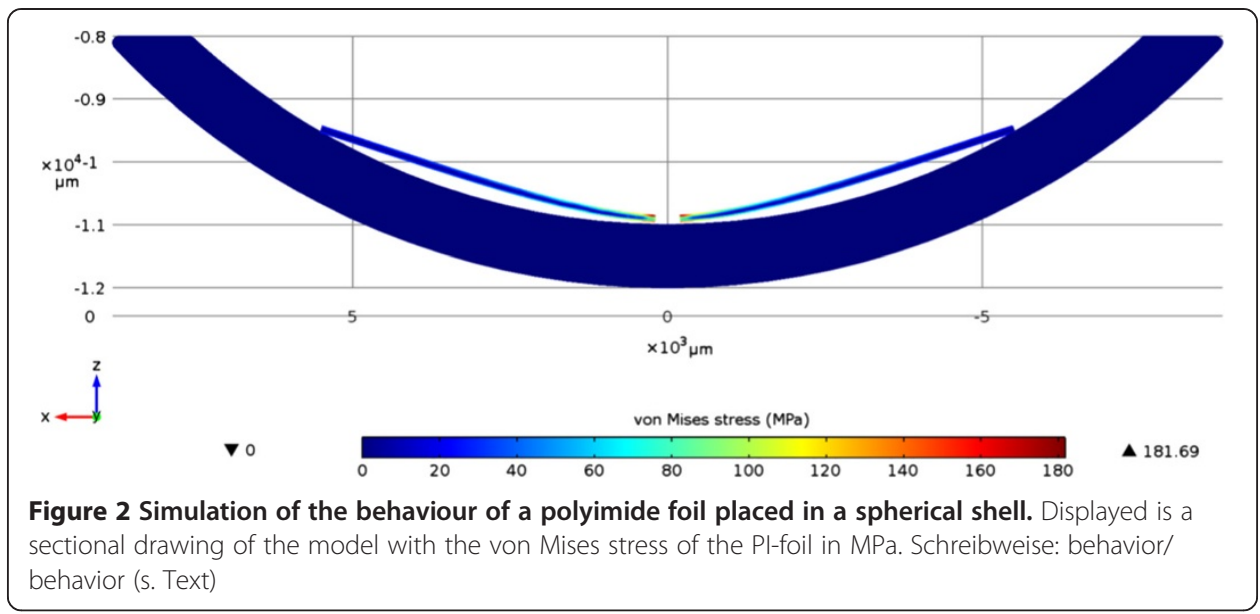

ground as well as at the outer edges. In between, the structure does not adapt to the curvature and eventually lifts up from the tissue. These issues can be addressed in two ways. The first method would be to create concentric segments within the structure. This would however make the handling of the structure more difficult during implantation. The other possibility is to create the devices with an inherent curvature. This could be done by utilizing the thermal and mechanical properties of the Parylene coating. As our primary concern is the handling of the stimulator during implantation we chose the second method.

\section{Material selection}

We integrated the MEA into the polyimide PI2611 (HD MicrosystemsTM GmbH, Neu-Isenburg, Germany) foil. The advantage of this material is its relatively low moisture uptake of $0.5 \%$, which helps to prolong the durability of the system embedded metallization layers in the prevailing wet conditions. Furthermore polyimide is characterized by a low relative dielectric constant of about 2.9, which also provides an excellent electric isolation of the feed lines of the electrodes. The low intrinsic stress of PI2611 makes it suitable as a base material for stimulators as the intended one. Additionally, polyimide can be easily structured via photolithographic techniques as it is soluble in the developer of standard photoresists. The Parylene $C$ encapsulation serves as an additional moisture barrier due to its hydrophobic behavior. Additionally Parylene $\mathrm{C}$ is moldable under the influence of elevated temperatures. This opens the possibility of creating curved structures [17].

The 250 electrodes of the final VLARS prototypes are circular shaped with a diameter of $100 \mu \mathrm{m} .25$ of the electrodes were connected to an external plug connector for stimulation and recording purposes. The impedance spectra of the electrodes of three devices are shown in Figure 3. At $1 \mathrm{kHz}$, a common stimulation frequency, the average impedance varies around $2 \mathrm{k} \Omega$ for all devices. The standard deviation is around $500 \Omega$. Figure 4 shows a cyclovoltametric $(\mathrm{CV})$ measurement of the iridium oxide electrodes. It was carried out in a voltage range of $-0.8 \mathrm{~V}$ to $0.9 \mathrm{~V}$ with a ramp speed of $100 \mathrm{mV} / \mathrm{s}$. The calculated charge delivery capacities of the VLARS electrodes are in the range of 40 to $50 \mathrm{mC} / \mathrm{cm}^{2}$, which is consistent with the literature [18]. 


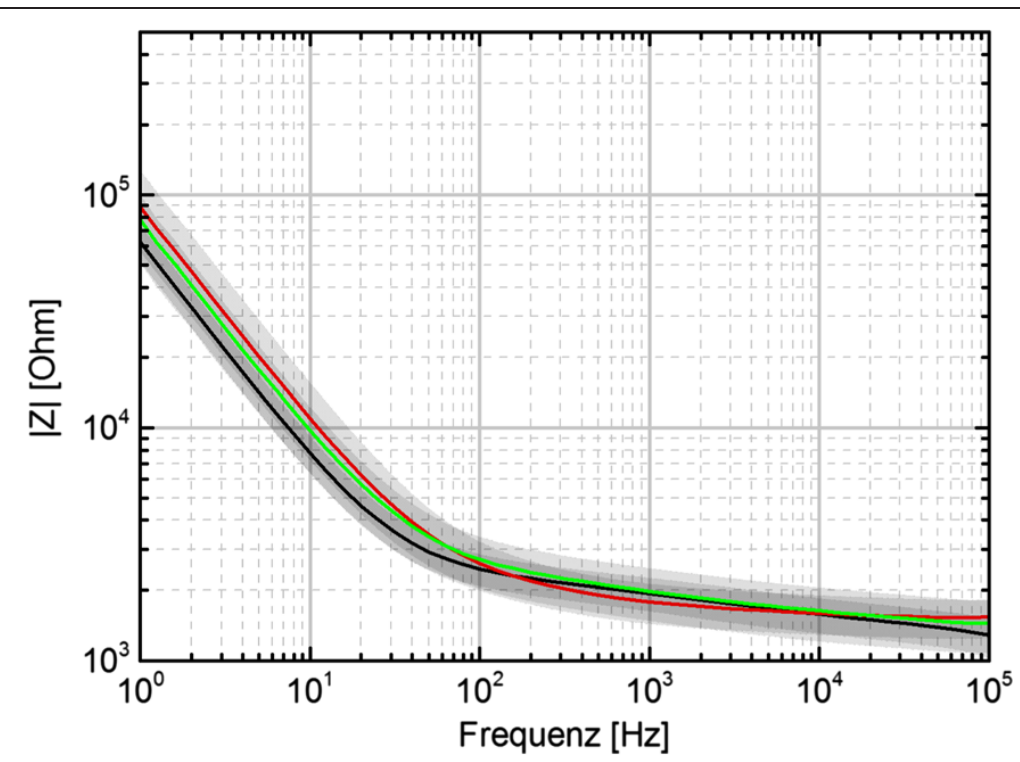

Figure 3 Impedance spectra from electrodes of three VLARS devices. Each of the colored lines show the average of all 25 electrodes of one device. The grey areas represent the standard deviation.

\section{Shape selection and design modification}

Figure 5 shows the different designs of the first generation that were tested in enucleated porcine eyes. A continuous, circular shape (D1) served as control. A spiral shape (D2) was constructed because we thought that it could be easily inserted by turning the device arms through a small sclerotomy. Moreover, slits between the spiral windings would have allowed a better fitting to the surface profile of the retina. However, implantation revealed remarkable problems of handling and placing the soft implant onto

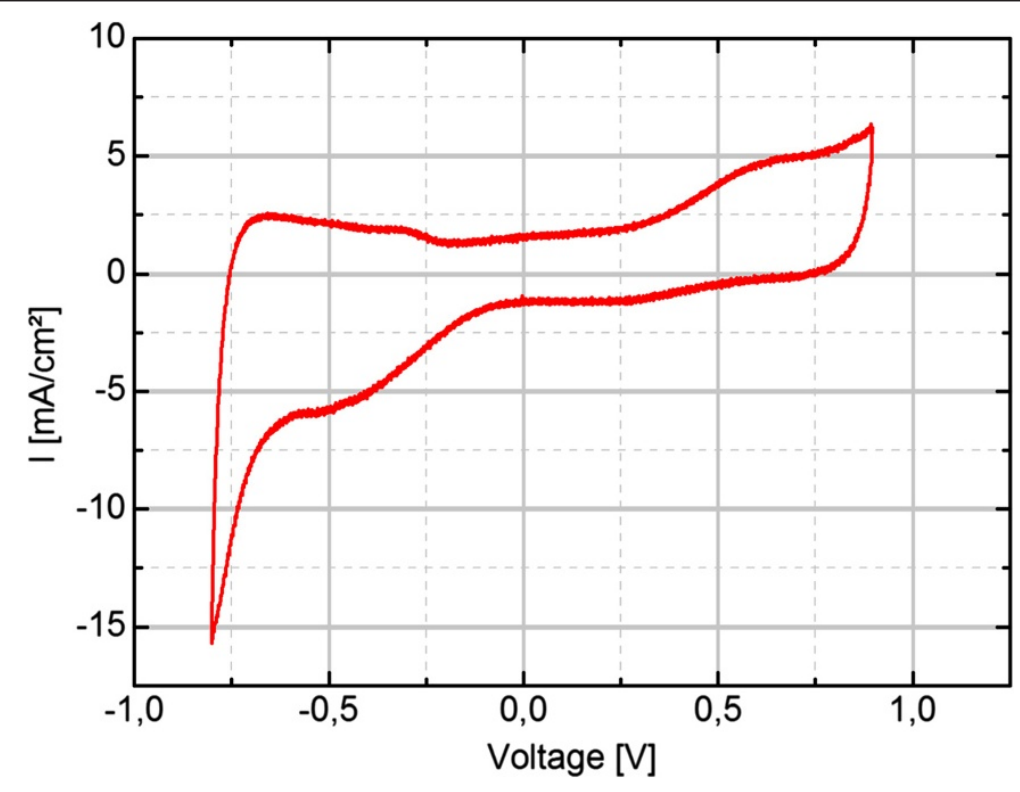

Figure 4 Typical cyclovoltametry measurement of VLARS electrodes. 


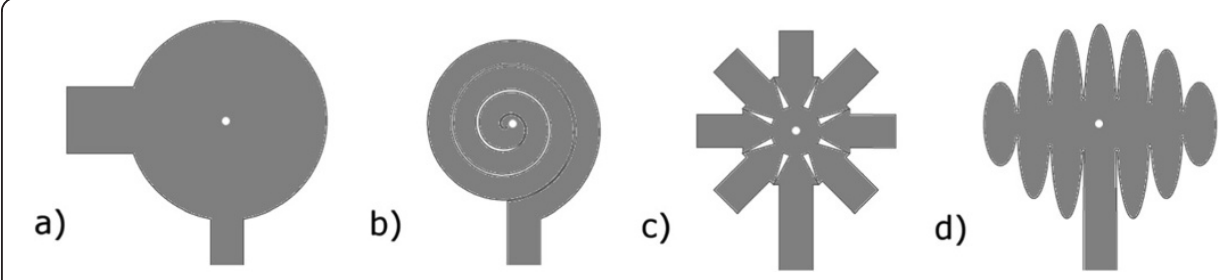

Figure 5 Designs of the first generation of VLARS-prototypes showing the designs D1 (a), D2 (b), D3 (c) and D4 (d).

the retinal surface. Additionally, the structure design included an increased risk of material damage during implantation.

The star-like shape (D3) was designed because of its theoretical very good unfolding potential. During insertion (surgery) the arms were properly (nicely) bent back and regained their original shape inside the eye without damage of the device structure. Also it fits well to the curvature of the eyeball. The globe design (D4) is based on the principle of an interrupted cylindrical projection of a spherical structure on a flat surface.

All first generation designs D1-4 had a central hole for tack fixation. Additional holes were provided in the periphery of the structure to be used if necessary to support the primary fixation and keep the electrodes in contact with the retina.

Following first implantation experiments in porcine eyes the prototypes D3 and D4 were selected for further development. Both designs were modified in a way that the effective area was enlarged by reducing the gaps between the blades and by increasing their number as shown in Figure 6. The symmetry of the patterns is abandoned to provide the highest density of electrodes in the center of the structure for stimulation of the foveal region whereas in the more peripheral areas the electrode density is less corresponding to the lower density of ganglion cells and the lower spatial resolution provided by these retinal areas. The tack fixation site was moved from the center to a distant position opposite to the optic nerve head to reduce the effect of tissue reaction at the tack on the stimulation process.

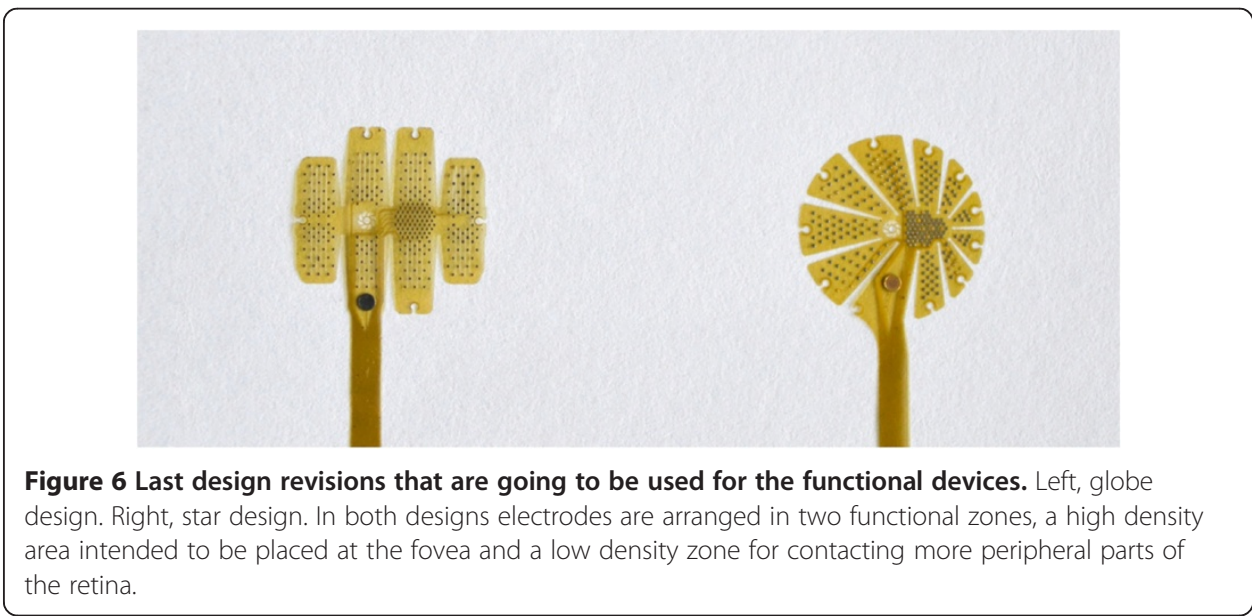




\section{Surgical simulation}

Implantation tests in enucleated eyes of pigs and rabbits demonstrated that a transscleral approach to insert these devices may cause a phase of severe hypotony even if the eye was filled with perfluorocarbon liquids (PFCLs) and even if a PFCL filled nozzle was used as an insertion aid. Insertion was easier and better controlled if the stimulator was positioned through a corneal incision as seen in Figure 7. It was also evident, that the D3 and D4 designs were much more suitable in terms of smooth folding and unfolding. Both devices could be fixated onto the retinal surface using a single retinal tack (Figure 7, right panel). The surgeon rated the procedure as complex but feasible and safe. This rating does not differ from ratings of implantation of clinically available retinal implants such as the ARGUS II device.

We measured the ohmic resistance between the contact pads and the respective electrodes before and after an implantation experiment to verify, that no damage was done to the electric wiring. Figure 8 shows no significant change in the ohmic resistance on any of the electrodes.

\section{Preliminary test on recording capabilities}

The VLARS MEA was connected to the MEA2100-Setup as shown in Figure 9. On the region with the highest electrode density (foveal region), a piece of Wistar wild-type retina was placed with the ganglion cell layer facing the electrodes. For a preliminary assessment of stimulation and recording properties of the VLARS MEA a biphasic current pulse was delivered at one electrode. The stimulation artefact recorded from an adjacent electrode was clearly visible but also a neural response with increased spike activity after the pulse as shown in Figures 10 and 11. In Figure 11 every spike is indicated as a black bar and every row shows one trial. The perievent histogram (Figure 11, lower traces) summarizes the data of the individual stimulation trials.

In addition to the studies of the electrical stimulation properties, the recording characteristics of the device were examined in further experiments. Figure 12 (upper trace) demonstrates that spontaneous firing activity of a retinal ganglion cells could be recorded with spikes clearly detectable. In further experiments, the retina was illuminated for 1 second with a white light flash. The response to the light pulse could be monitored at several electrodes as an increased firing activity of the displayed ganglion cell (Figure 12, lower trace). The apparent action potentials were sorted and analyzed. Figure 13 (upper

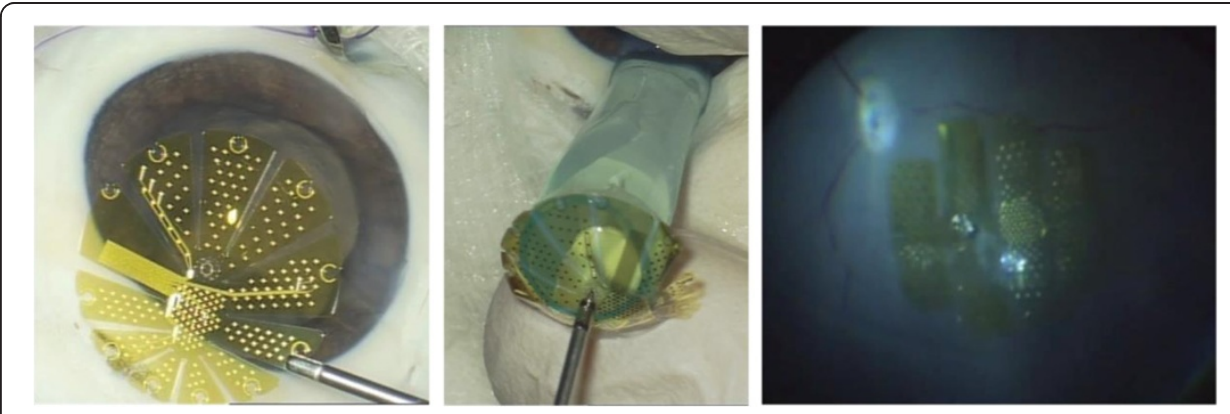

Figure 7 Left: VLARS MEA with star design before implantation into the pig eye. Center: Insertion of the VLARS MEA into the implantation nozzle. Right: Globe type MEA placed onto the retinal surface of a pig eye and fixated with a retinal tack. 


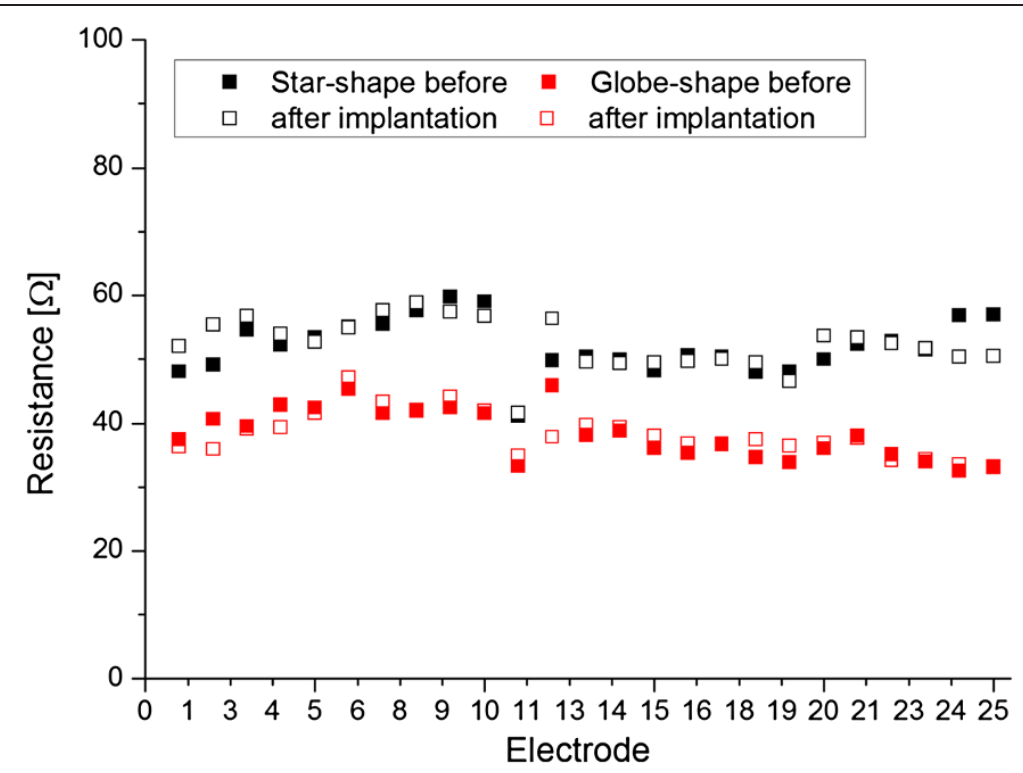

Figure 8 Measurements of the ohmic resistance of the contacted electrodes before and after implantation shows no signs of damage by the implantation experiment.

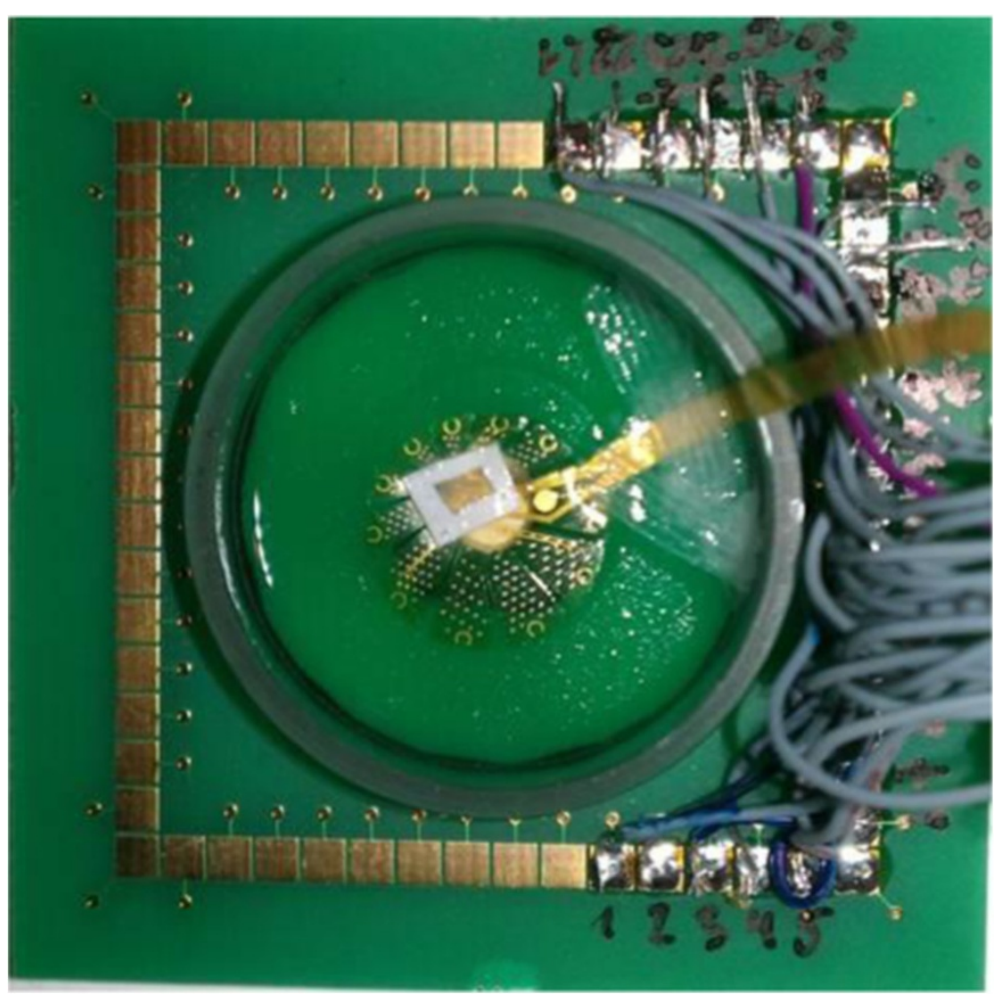

Figure 9 Functional testing of a star type VLARS MEA. For recording of spontaneous and evoked spike activity a piece of the retina (arrow) from a Wistar rat was placed with the ganglion cell layer onto the VLARS-MEA. The bond pads on the right are connected to the MEA hardware equipment for recording and stimulation. The wires connect each of 25 active VLARS electrodes with the bond pads. 


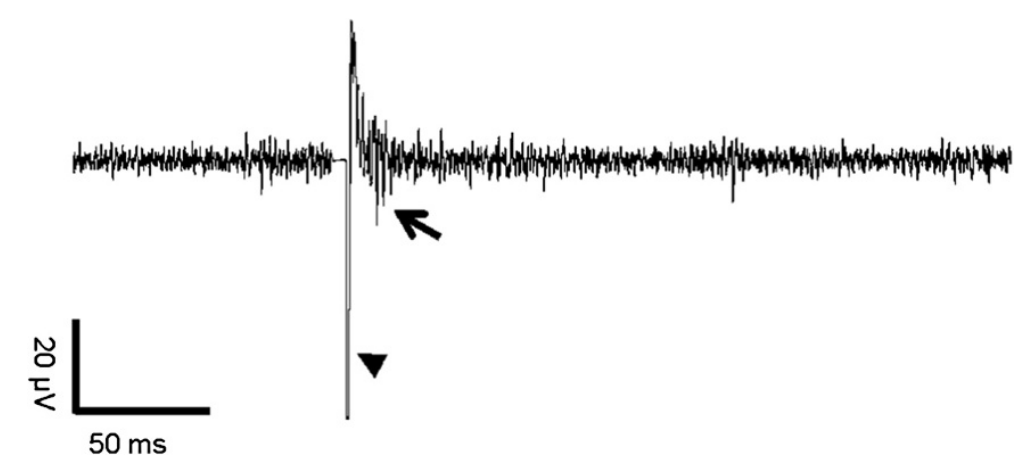

Figure 10 Monitoring of neural activity after stimulation in the isolated rat retina using a VLARS

MEA. Arrowhead shows the stimulation artifact of the biphasic current pulse. The neural response could be detected as evoked spikes marked with an arrow.

traces) shows the responses to light stimulation of four trials in a perievent raster plot. Every spike is figured as a black bar and every row shows one trial. Illumination started at time-point 0 . The time range from $-0.5 \mathrm{~s}$ to $0 \mathrm{~s}$ indicates the spontaneous firing activity of the neuron under red light. The perievent histogram (Figure 13, lower traces) summarizes the data of the individual light trials. After about $80 \mathrm{~ms}$ an increase of the spiking activity could be recorded as a response to the light stimulus. With the VLARS MEA it was possible to monitor light responses at seven of the nine connected foveal electrodes.

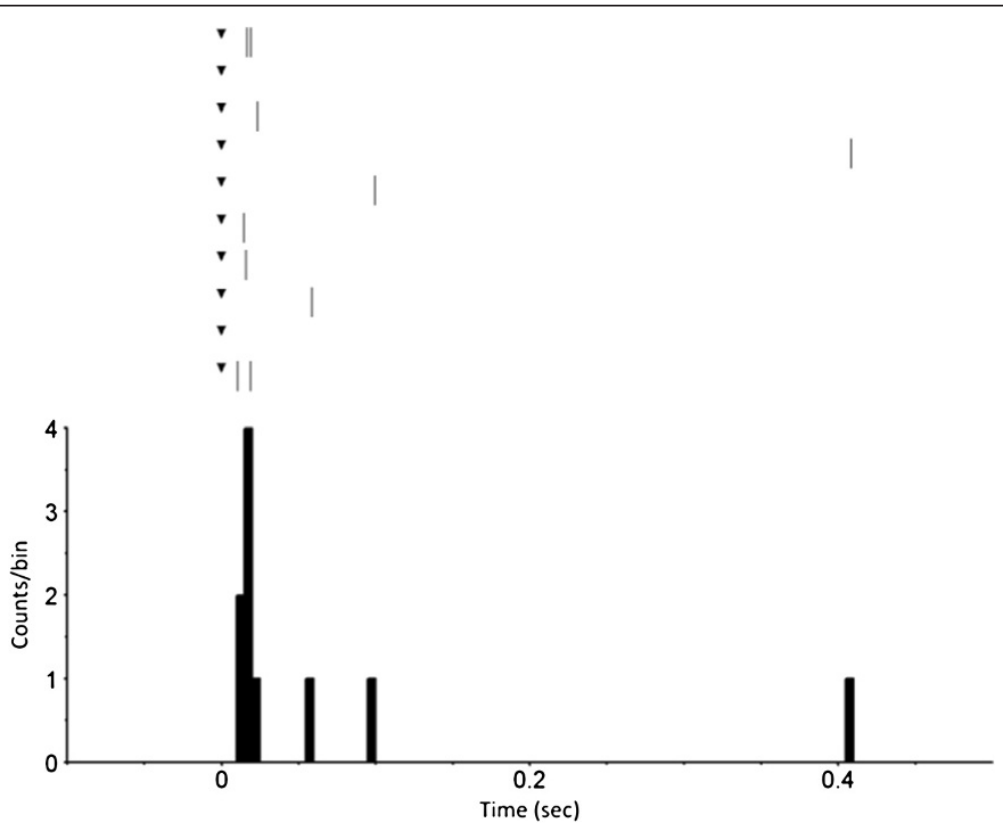

Figure 11 Perievent raster with histogram of 10 trials. The response of a wild type Wistar rat retinal ganglion cell to a biphasic current pulse recorded with a VLARS MEA. The pulse started at time point " 0 " (black triangle). The perievent histrogram (lower trace) summarizes the results of the corresponding perievent raster (upper traces). The neural response could be detected immediately after stimulation. Bin size $5 \mathrm{~ms}$. 

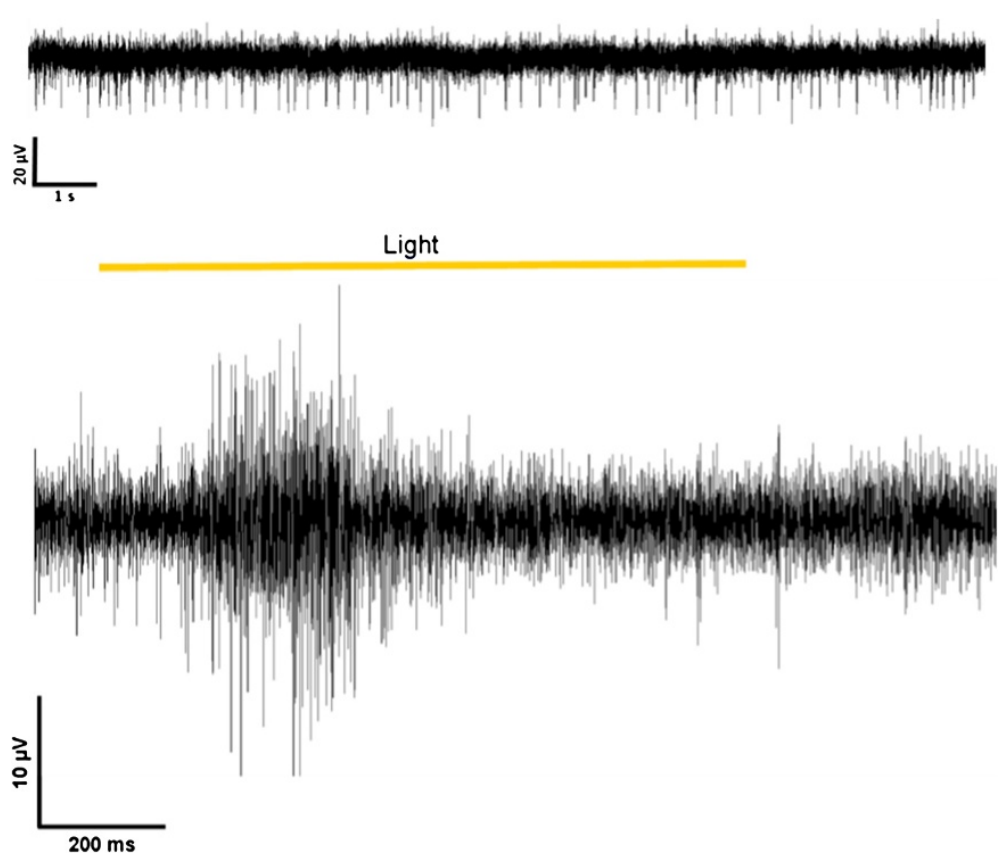

Figure 12 Monitoring of neural activity in the isolated rat retina using a VLARS MEA. Top, spontaneous spiking activity of retinal ganglion cells. Bottom, ganglion cell response to light stimulation. Representative recording from one of the connected electrodes.

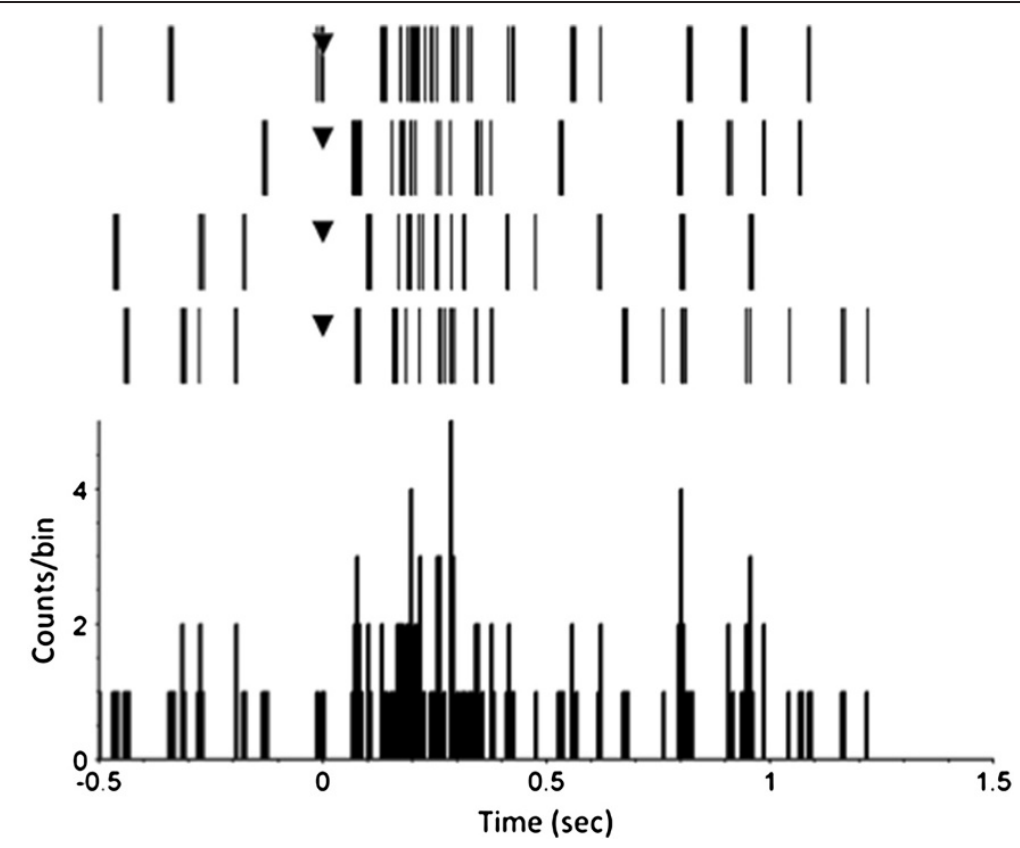

Figure 13 Perievent raster with histogram of four trials. The response of a wild type Wistar rat retinal ganglion cell to a one second white light flash recorded with a VLARS MEA. The illumination started at time point "0" (black triangle). The graph shows spontaneous activity 500 ms before stimulus onset, the response during the one second light stimulus and the activity $500 \mathrm{~ms}$ after illumination. Bin size $5 \mathrm{~ms}$. 


\section{Discussion}

Stimulators covering a large area of the retinal surface needed to be fitted to the retinal surface topography. The inner surface of the eye is different from an ideal spherical curvature and moreover due to different axial sizes of eyes the inner curvature also differs within individuals. Despite the fact that, individually designed and fabricated stimulators would be great to ensure a perfect fit with the individual surface topography, but the first step in the development of large arrays is the fabrication of a general design which fits for many sizes of eyes as a proof of concept device. Larger variations are considerably increasing the complexity of the fabrication process and are currently not regarded as useful since e.g. very small eyes such as in young children are not considered to be implanted with retinal implants. Implant structures specially designed for animal experiments covering an extreme variety of eye sizes from mouse to pigs were not planned to be fabricated within this project.

In the foveal region the image size on the retina is nearly proportional to the visual angle. An image covering three millimeters in length on the retina corresponds to a visual angle of approximately 10 degrees [19]. Moreover, it has been shown that there is a strong correlation between the position of the stimulating electrode on the retinal surface and the response within the visual cortex and the visual field, respectively [20,21].

Retinal stimulator MEAs can be placed either underneath the retina as subretinal devices or onto the retinal surface as epiretinal devices [7-10]. Both approaches have in common that current prototypes are designed for stimulation of the foveal region which may allow a visual angle of about $10^{\circ}-18^{\circ}$ or $5^{\circ}-9^{\circ}$ of visual field, respectively.

The VLARS project was started to develop a stimulator MEA covering a larger visual field. We built a device with a diameter of 12 millimeters covering a retinal area of about $110 \mathrm{~mm}^{2}$. A retinal stimulator of that size could restore a visual field of about $18.8^{\circ}$ covering a corresponding visual angle of $37.6^{\circ}$ when implanted in a human eye of normal size. Additionally, more than 250 electrodes can be placed on such a device with current available technology.

Large stimulators were also suggested by Villalobos et al. and the Bionic Vision Australia Group: They described a MEA which can be placed in the suprachoroidal space with dimensions of $8 \times 13 \mathrm{~mm}$, providing a visual angle in the human eye of about $27.14 \times 39.8^{\circ}$ or a visual field of $13.6 \times 19.9^{\circ}$. MEA systems not in direct contact with the retina seemed to be limited in terms of spatial resolution because of the distance between the active electrodes and the target neurons. The advantage of suprachoroidal implants however might be the low risk profile of the surgery [22,23].

Studies on the safety of the EPIRET III device, which was also based on polyimide and contained similar materials and the same encapsulation as the VLARS prototypes confirmed a good biocompatibility and function of the implants [24-27]. For epiretinal fixation of the device retinal tacks have been shown to provide direct contact of the electrode array to the retinal surface-a prerequisite for successful retinal ganglion cell stimulation (re-detected and re-established) [28-30]. While the fixation of small stimulators requires up to two retinal tacks $[7,8]$ it requires further experiments to determine if larger devices will need more elements for fixation. For this reason our next step will be the implantation in animal experiments to prove the biocompatibility of the device and during follow-up examinations to quantify the number of necessary tacks. As optical coherence tomography (OCT) has been successfully used to demonstrate the 
contact of epiretinal stimulators with the retinal surface [31], this examination procedure will be used for the upcoming experiments. Moreover, stimulating tests will be performed to determine and to evaluate stimulation thresholds of different electrodes in regard to the retinal contact of each part of the stimulator. Alternative approaches to avoid mechanical fixation tools have been described in animal experiments but were not used clinically: Thermosensitive glues and biochemical adhesion provided by immobilized peptide chains have been used in experimental settings [32,33]. In the future these approaches may help to reduce the amount of retinal tacks for fixation of large epiretinal stimulators.

The main concern for large stimulators is the possibility of intra- or postoperative complications. The larger incision necessary to implant such devices into an eye could cause a higher risk of infection, high astigmatism, leakage, and proliferative tissue reactions. Therefore, a flexible device is desirable which can be inserted through a smaller incision. Our experiments on enucleated pig and rabbit eyes showed that when using a nozzle the folded device could be inserted through an incision of 5-6 $\mathrm{mm}$, which seems to be reasonable in terms of risk profile. Stimulation tests and impedance measurements on implanted devices are necessary to demonstrate that stimulators endure the implantation without any damage.

Currently available epiretinal implants have certain drawbacks not only concerning their stimulator size but also concerning electrode size and material, and stimulation algorithms. To yield better spatial resolution a higher density of electrodes is desirable although that usually means to design smaller electrodes with a greater risk of adverse electrochemical reactions at their surface. Such electrochemical reactions have to be avoided by proper selection of the electrode surface material. Stimulation algorithms usually do not take into account that not only ganglion cells may be stimulated but also other excitable cells like amacrine cells or even bipolar cells [34]. The activation of possibly inhibiting local neural networks in the degenerated retina may prevent useful ganglion cell activity. Furthermore, high current or voltage stimulation could evoke action potentials in axons whose somatas are far away from the stimulation site. This may induce percepts coming from a retinal region unrelated to the position of the electrode $[35,36]$. These factors have to be taken also into account when future implant concepts are discussed. However, the enlargement of the stimulator area may be one step towards a larger visual field in otherwise blind subjects.

We were able to demonstrate in a preliminary experiment, that the device is useful for electrical stimulation of the retina and that it also has the potential to record neural network activity. The latter allows the realization of bidirectional implants capable to record from the target tissue and to stimulate the tissue. The recordings could probably be used to automatically modify and optimize the stimulation pattern, which is usually based on image characteristics and fixed assumptions on the functional state of the retina.

\section{Conclusions}

The successful fabrication of VLARS prototypes and the promising observations concerning surgical handling, stimulation and recording represent first steps in the realization of a large stimulating array for wide-field direct epiretinal stimulation to generate artificial vision with enlarged visual fields. Further experiments are necessary to demonstrate its long-term biocompatibility in-vivo and also its stimulation properties. 


\section{Competing interests}

The authors declare that they have no competing interests.

\section{Authors' contributions}

FW performed the CAD design of the prototypes and simulated the mechanical properties of the VLARS MEAs and fabricated the prototypes under the supervision of WM. He wrote significant parts of the manuscript. SH did the recording and stimulation experiments with the VLARS MEAs and wrote the specific parts of the manuscript. ACR and TL prepared the surgical experiments and were responsible for the documentation. They did the literature search. $\mathrm{CB}$ and TLaube assisted in the surgical experiments and contributed extensively to the design concepts discussion and handling evaluation. NB, WM, GT, SJ, and PW developed the concept of VLARS MEAs, wrote the grant application, and wrote significant parts of the manuscript. They finally approved the paper. GR and GT performed the surgical handling tests and wrote the corresponding sections of the manuscript. All authors read and approved the final manuscript.

\section{Acknowledgment}

This work was supported by a grant of the Jackstädt Foundation "VLARS".

SH was supported by DFG grants WA 1472/6-1, TH 603/15-1, MU 3036/3-1.

\section{Author details}

IInstitute for Materials in Electrical Engineering I, RWTH Aachen University, Sommerfeldstr 24, 52074 Aachen, Germany. ${ }^{2}$ Department of Ophthalmology, University Hospital Aachen, RWTH Aachen University, Pauwelsstr 30, 52074 Aachen, Germany. ${ }^{3}$ Department of Ophthalmology, University Hospital Essen, Hufelandstr 55, 45147 Essen, Germany. ${ }^{4}$ Hôpitaux universitaires de Genève, Service d'ophtalmologie, Rue Alcide-Jentzer 22, CH-1211 Genève 14, Suisse.

Received: 20 August 2013 Accepted: 29 January 2014

Published: 6 February 2014

\section{References}

1. Daiger SP, Bowne SJ, Sullivan LS: Perspective on genes and mutations causing retinitis pigmentosa. Arch Ophthalmol 2007, 125:151-158.

2. Aldahmesh MA, Abu Safieh L, Alkuraya H, Al-Rajhi A, Shamseldin H, Hashem M, Alzahrani F, Khan AO, Alqahtani F, Rahbeeni Z, Alowain M, Khalak H, Al-Hazzaa S, Meyer BF, Alkuraya FS: Molecular characterization of retinitis pigmentosa in Saudi Arabia. Mol Vis 2009, 15:2464-2469.

3. Bunker CH, Berson EL, Bromley WC, Hayes RP, Roderick TH: Prevalence of retinitis pigmentosa in Maine. Am J Ophthalmol 1984, 97:357-365.

4. Humayun MS, de Juan E, Dagnelie G Jr, Greenberg RJ, Propst RH, Philips DH: Visual perception elicited by electrical stimulation of retina in blind humans. Arch Ophthalmol 1996, 114:40-46.

5. Hornig R, Laube T, Walter P, Velikay-Parel M, Bornfeld N, Feucht M, Akguel H, Rössler G, Alteheld N, Lütke Notarp B, Wyatt J, Richard G: A method and technical equipment for an acute human trial to evaluate retinal implant technology. J Neural Eng 2005, 2:129-134.

6. Keserü M, Feucht M, Bornfeld N, Laube T, Walter P, Rössler G, Velikay-Parel M, Hornig R, Richard G: Acute electrical stimulation of the human retina with an epiretinal electrode array. Acta Ophthalmol 2012, 90:e1-e8.

7. Yanai D, Weiland JD, Mahadevappa M, Greenberg RJ, Fine I, Humayun MS: Visual performance using a retinal prosthesis in three subjects with retinitis pigmentosa. Am J Ophthalmol 2007, 143:820-827.

8. Roessler G, Laube T, Brockmann C, Kirschkamp T, Mazinani B, Goertz M, Koch C, Krisch I, Sellhaus B, Trieu HK, Weis J, Bornfeld N Rothgen H, Messner A, Mokwa W, Walter P: Implantation and explantation of a wireless epiretinal retina implant device: observations during the EPIRET3 prospective clinical trial. Invest Ophthalmol Vis Sci 2009, 50:3003-3008.

9. Benav H, Bartz-Schmidt KU, Besch D, Bruckmann A, Gekeler F, Greppmaier U, Harscher A, Kibbel S, Kusnyerik A, Peters T, Sachs H, Stett A, Stingl K, Wilhelm B, Wilke R, Wrobel W, Zrenner E: Restoration of useful vision up to letter recognition capabilities using subretinal microphotodiodes. Conf Proc IEEE Eng Med Biol Soc 2010, 1:5919-5922.

10. Menzel-Severing J, Laube T, Brockmann C, Bornfeld N, Mokwa W, Mazinani B, Walter P, Roessler G: Implantation and explantation of an active epiretinal visual prosthesis: 2-year follow-up data from the EPIRET3 prospective clinical trial. Eye (Lond) 2012, 26(4):501-509.

11. Eckmiller R: Learning retina implants with epiretinal contacts. Ophthalmic Res 1997, 29:281-289.

12. Stieglitz T, Beutel H, Keller R, Blau C, Meyer JU: Development of flexible stimulation devices for a retina implant system. Conf Proc IEEE Eng Med Biol Soc 1997, 5:2307-2310.

13. Mokwa W, Goertz M, Koch C, Krisch I, Trieu HK, Walter P: Intraocular epiretinal prosthesis to restore vision in blind humans. Conf Proc IEEE Eng Med Biol Soc 2008, 1-8:5790-5793.

14. Patel KS, Kohl PA, Bidstrup Allen SA: Dual capacitor technique for measurement of through-plane modulus of thin polymer films. J Polym Sci B 2000, 38(12):1634-1644.

15. Koch C, Fassbender H, Nolten U, Goertz M, Mokwa W: Fabrication and assembly techniques for a 3rd generation wireless epiretinal prosthesis. Aachen, Germany: Proc. of MME 2008, 19th Workshop on Micromachining, Micromechanics and Microsystems; 2008:365-368. ISBN: 978-3-00-025529-8.

16. Mokwa W, Görtz M, Koch C, Krisch I, Trieu HK, Walter P: Intraocular epiretinal Prothesis to restore vision in blind humans. In Proc. of the 30th Annual International Conference of the IEEE Engineering in Medicine and Biology Society, Vancouver. Piscataway, NJ, USA: EMBS; 2008:5790-5793.

17. Rodger DC, Fong AJ, Li W, Ameri H, Ahuja AK, Gutierrez C, Lavrov I, Zhong H, Menon PR, Meng E, Burdick JW, Roy $R R$, Edgerton VR, Weiland JD, Humayun MS, Tai YC: Flexible parylene-based multielectrode array technology for high-density neural stimulation and recording. Sens Actuators B 2008, 132(2):449-460. ISSN 0925-4005, http://dx. doi.org/10.1016/j.snb.2007.10.069. 
18. Wessling B, Mokwa W, Schnakenberg U: RF-sputtering of iridium oxide to be used as stimulation material in functional medical implants. J Micromech Microeng 2006, 16(6):S142-S148.

19. Drasdo N, Fowler CW: Non-linear projection of the retinal image in a wide-angle schematic eye. $\mathrm{Br} J$ Ophthalmol 1974, 58:709.

20. Eckhorn R, Wilms M, Schanze T, Eger M, Hesse L, Eysel UT, Kisvarday ZF, Zrenner E, Gekeler F, Schwahn H, Shinoda $\mathrm{K}$, Sachs $\mathrm{H}$, Walter P: Visual resolution with retinal implants estimated from recordings in cat visual cortex. Vision Res 2006, 46(17):2675-2690.

21. Walter P, Kisvárday ZF, Görtz M, Alteheld N, Rossler G, Stieglitz T, Eysel UT: Cortical activation via an implanted wireless retinal prosthesis. Invest Ophthalmol Vis Sci 2005, 46(5):1780-1785.

22. Ameri H, Ratanapakorn T, Ufer S, Eekhardt H, Humayun MS, Weiland JD: Toward wide-field retinal prosthesis. J Neural Eng 2009, 1:6(3).

23. Villalobos J, Allen PJ, McCombe MF, Ulaganathan M, Zamir E, Ng DC, Shepherd RK, Williams CE: Development of a surgical approach for a wide-view suprachoroida retinal prosthesis: evaluation of implantation trauma. Graefes Arch Clin Exp Ophthalmol 2012, 250:399-407.

24. Klauke S, Goertz M, Rein S, Hoehl D, Thomas U, Eckhorn R, Bremmer F, Wachtler T: Stimulation with a wireless intraocular epiretinal implant elicits visual percepts in blind humans. Invest Ophthalmol Vis Sci 2011, 52:449-455.

25. Walter P, Szurman P, Vobig M, Berk H, Ludtke-Handjery HC, Richter H, Mittermayer C, Heimann K, Sellhaus B: Successful long-term implantation of electrically inactive epiretinal microelectrode arrays in rabbits. Retina 1999, 19:546-552.

26. Menzel-Severing J, Sellhaus B, Laube T, Brockmann C, Bornfeld N, Walter P, Roessler G: Surgical results and microscopic analysis of the tissue reaction following implantation and explantation of an intraocular implant for epiretinal stimulation in minipigs. Ophthalmic Res 2011, 46:192-198.

27. Laube T, Brockmann C, Roessler G, Walter P, Krueger C, Goertz M, Klauke S, Bornfeld N: Development of surgical techniques for implantation of a wireless intraocular epiretinal retina implant in Göttingen minipigs. Graefes Arch Clin Exp Ophthalmol 2012, 250:51-59.

28. Ando F, Kondo J: A plastic tack for the treatment of retinal detachment with giant tear. Am J Ophthalmol 1983, 95:260-261.

29. de Juan E, Machemer R: Retinal tacks. Am J Ophthalmol 1985, 99:272-274.

30. Maji AB, Humayun MS, Weiland JD, Suzuki S, D'Anna SA, de Juan E Jr: Long-term histological and electrophysiological results of an inactive epiretinal electrode array implantation in dogs. Invest Ophthalmol Vis Sci 1999, 40:2073-2081.

31. Ahuja AK, Yeoh J, Dorn JD, Caspi A, Wuyyuru V, McMahon MJ, Humayun MS, Greenberg RJ, Dacruz L: Factors affecting perceptual threshold in Argus II retinal prosthesis subjects. TransI Vis Sci Technol 2013, 2(4):1. Epub 2013 Apr 12.

32. Roessler G, Klee D, Mokwa W, Alteheld N, Harwardt M, Koch C, Hungar K, Sellhaus B, Walter P: Development of biochemically modified inactive retinal implants for fixation testing in animal experiments [abstract]. Invest Ophthalmol Vis Sci 2006, 47:3175. ARVO E-Abstract.

33. Tunc $M$, Humayun $M$, Xuanghong C, Ratner BD: A reversible thermosensitive adhesive for retinal implants. Retina 2008, 28:1338-1343.

34. Margalit E, Babai N, Luo J, Thoreson WB: Inner and outer retinal mechanisms engaged by epiretinal stimulation in normal and rd mice. Vis Neurosci 2011, 28:145-154.

35. Fried SI, Lasker ACW, Desai NJ, Eddington DK, Rizzo JF: Axonal sodium-channel bands shape the response to electric stimulation in retinal ganglion cells. J Neurophysiol 2009, 101:1972-1987.

36. Jensen RJ, Rizzo JF, Ziv R, Grumet A, Wyatt J: Thresholds for activation of rabbit retinal ganglion cells with an ultrafine, extracellular microelectrode. Invest Ophthalmol Vis Sci 2003, 44:3533-3543.

doi:10.1186/1475-925X-13-11

Cite this article as: Waschkowski et al: Development of very large electrode arrays for epiretinal stimulation (VLARS). BioMedical Engineering OnLine 2014 13:11.

\section{Submit your next manuscript to BioMed Central and take full advantage of:}

- Convenient online submission

- Thorough peer review

- No space constraints or color figure charges

- Immediate publication on acceptance

- Inclusion in PubMed, CAS, Scopus and Google Scholar

- Research which is freely available for redistribution 